\title{
Nitrogen-functionalized Isohexides in Asymmetric Induction
}

\author{
Marine Janvier, Sylvie Moebs-Sanchez, and Florence Popowycz*
}

\begin{abstract}
Biosourced isohexides have attracted the considerable attention of both the academic and industrial chemistry communities over the last 50 years. This highlight focuses on the synthesis of nitrogen-containing isohexides and their applications in asymmetric catalysis.
\end{abstract}

Keywords: Asymmetric catalysis · Isohexides

For the past few decades, the academic landscape has been strongly modified due to the concepts issuing from 'green chemistry'. Even if some terminology was finally established by Trost, ${ }^{[1]}$ Sheldon ${ }^{[2]}$ and Anastas, ${ }^{[3]}$ for their contribution to the atom economy principle, the $\mathrm{E}$ factor definition and the twelve principles of green chemistry, pioneering work in this field should be acknowledged as originating from Giacomo Ciamician in 1908. As a confirmation of his thoughts, the use of renewable materials or reagents is now clearly indexed as Principle 7.[4]

Isosorbide $\mathbf{1}$ is a chiral dianhydrohexitol and a major product of the starch industry produced by Roquette Frères (Lestrem, France $)^{[5]}$ that expanded its production to several thousand tons in 2011. The industrial process is initiated by double dehydration of sorbitol. The hydroxyl group on the $\mathrm{C}_{6}$ position has an exo configuration (pointing out from the cycle) whereas the one on $\mathrm{C}_{3}$ has an endo configuration (pointing into the cycle) (Fig. 1). As a consequence, two pivotal parameters have been highlighted to influence the native reactivity: i) hydrogen bonding between the endo-hydroxyl group and the endocyclic oxygen; ii) steric hindrance of the endo-hydroxyl group compared to the exo one.
Along with isosorbide, the family of 1,4:3,6-dianhydrohexitols is completed with two other symmetrical diastereomers: isomannide 2 (endolendo isomer) and isoidide 3 (exolexo isomer) (Fig. 1). Double dehydration of D-mannitol and D-glucitol have afforded isomannide and isosorbide in a wide range of acidic conditions such as formic acid/HF, ${ }^{6]}$ pyridinium chloride, ${ }^{[7]}$ $\mathrm{H}_{2} \mathrm{SO}_{4},{ }^{[8]}$ Amberlyst or Dowex resins, ${ }^{[9]}$ metal phosphates (of tin, zirconium, titanium, niobium), ${ }^{[10]}$ zeolites, ${ }^{[11]}$ silicotungstic acid ${ }^{[12]}$ and so on. Simple metallic or bifunctional catalysts also efficiently performed the dehydration of these polyols. [13] Cellulose ${ }^{[14]}$ could be directly converted by combining acidic and hydrogenation catalysts. Isoidide is the sole diastereomer that is not produced on industrial scale by double dehydration of L-iditol barely present in nature. Conformations of these bicyclic derivatives have been evaluated by NMR studies to be a combination of $\mathrm{C}_{\mathrm{S}}$ and $\mathrm{C}_{2}$ classical forms associated with cyclopentanes. ${ }^{[15]}$

Beyond the valorization of isohexides as chiral diols from renewable resources, most of all in polymer applications, ${ }^{[16]}$ the corresponding diamino-dideoxy isohexides 4-6 have recently attracted increased interest (Scheme 1). ${ }^{[17]}$ The importance of diamines as building blocks in the chemical industry and a growing aim to increase the sustainability and biocompatibility of the large-scale production of intermediates in the synthesis of polyamides and polyurethanes are highly motivating this research. ${ }^{[18]}$ Asymmetric induction is also another field of interest for valuable valorization of mono- and diamines, largely used as chiral auxiliaries and ligands. ${ }^{[19]}$ As a consequence, from the early 2000 s, isosorbide derivatives have been investigated in asymmetric catalysis. A few examples of enantioselective induction in the presence of nitrogen-containing isohexide derivatives have already been reported and will be presented in this contribution. ${ }^{[20]}$

\section{Synthesis of Nitrogen-containing Isohexide Derivatives}

\subsection{Preparation of Diamines}

Starting from dianhydrohexitols 1-3, primary diamines 4-6 were obtained by a classical three-step sequence of tosylation, azoturation (in DMF or in [bmim] $\mathrm{BF}_{4}{ }^{[21]}$ ) and hydrogenolysis (Scheme 1). ${ }^{[22]} \mathrm{Re}-$ placement of sodium azide by benzylamine and subsequent high-pressure hydrogenation allowed the access to diamines $\mathbf{4}$ and 5 with $50 \%$ and $61 \%$ global yield.[23] Unfortunately, when reacting isoidide ditosylate with ammonia ${ }^{[24]}$ or benzylamine, ${ }^{[17 b]}$ a tricyclic adduct 7 was isolated due to intramolecular nucleophilic substitution. Despite a poor atom-economy factor, the displacement by phthalimide, ${ }^{[17 a]}$ followed by acidic hydrolysis, was proposed as a more efficient scalable strategy to obtain $\mathbf{5}$

\footnotetext{
${ }^{\star}$ Correspondence: Prof. F. Popowycz Equipe Chimie Organique et Bioorganique Institut de Chimie et Biochimie Moléculaires et Supramoléculaires

Institut National des Sciences Appliquées (INSA Lyon) Bâtiment Jules Verne, 20 Avenue Albert Einstein F-69621 Villeurbanne Cedex

E-mail: florence.popowycz@insa-lyon.fr
}

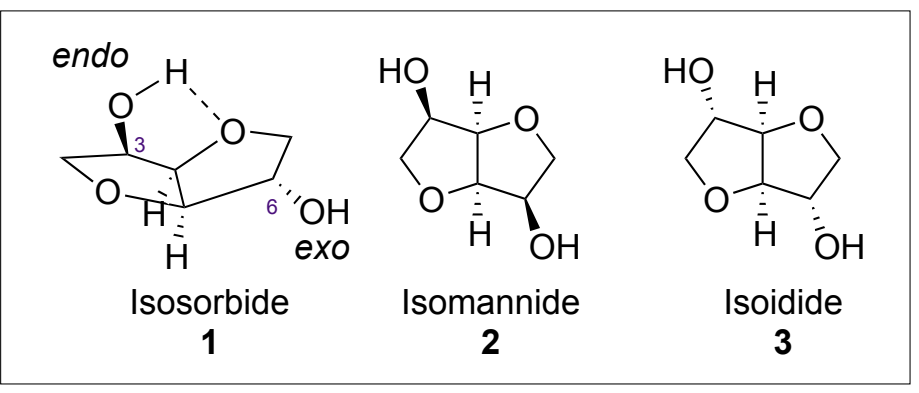

Fig. 1. Diastereomeric isohexides. 


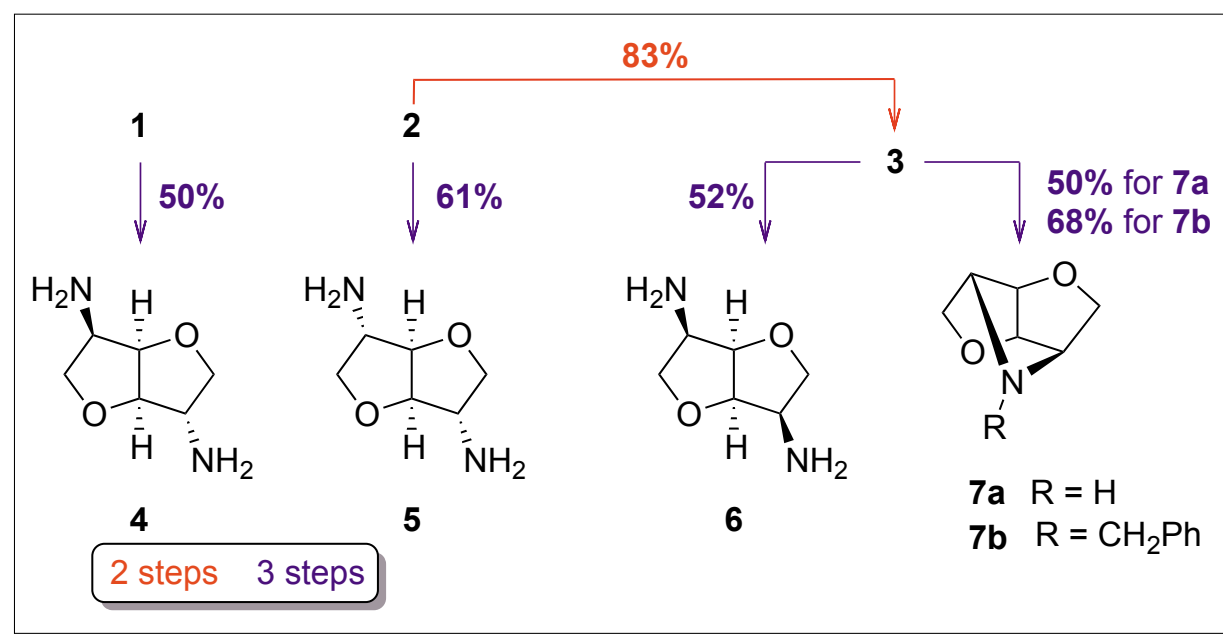

Scheme 1. Primary diamines arising from isohexides and side product.

on a multi-gram scale with high purity for step-growth polymerization.

To date, the least accessible diamine 6 is synthesized in five steps from isomannide 2 in $43 \%$ yield via a diazide intermediate $^{[25]}$ which breaks the defined safety rules. ${ }^{26]}$ More recently, Beller reported a ruthenium-catalyzed amination of isosorbide through a borrowing hydrogen reaction leading to an inseparable diastereomeric mixture of diamines 4-6 in an excellent $96 \%$ yield. ${ }^{[27]}$ As an alternative to metal-catalyzed amination, biocatalysis promoted by an enzymatic couple of transaminase/dehydrogenase only afforded isosorbide monoamine with $7 \%$ yield. ${ }^{[28]}$ These recent proofs of concepts opened the way to original sustainable and safer approaches, with, so far, no significant breakthrough regarding the synergistic efficiency and diastereoselectivity.

Nucleophilic substitution of ditriflated isomannide 8 by KCN (2.2 equiv.) in THF in the presence of crown-ether 18-C-6 (2.2 equiv.) provided dinitrile 9, which under reduction with an excess of borane, afforded homologated diamine 10 (Scheme 2). ${ }^{[29]}$

Depending on the nature of the nucleophilic species, secondary diamines (e.g. 12 and 14) as well as tertiary diamines could be prepared (Scheme 3 ). In our hands, initial substitution by $N$-methylbenzylamine of isosorbide ditosylate $\mathbf{1 1}$ afforded an intermediate, easily isolable, tertiary amine. Upon treatment with ammonium formate, in the presence of 1 mass equivalent of palladium, bis-secondary methyl amine 12 was obtained in $80 \%$ yield (Scheme 3 ). Nevertheless, direct substitution with low boiling point amines (methylamine, allylamine, diallylamine) failed resulting in complete recovery of the starting material.

Subsequent quaternization of secondary amine $\mathbf{1 4}$ provided biosourced ionic liquids (bis-ammonium 15, 16 ${ }^{[30]}$ or bisimidazolium $\mathbf{1 7}^{[31]}$ ). Ammonium and im- idazolium ionic liquids were investigated for their physical and chemical properties such as low vapor pressure, high thermal stability, ionic conductivity, offering new

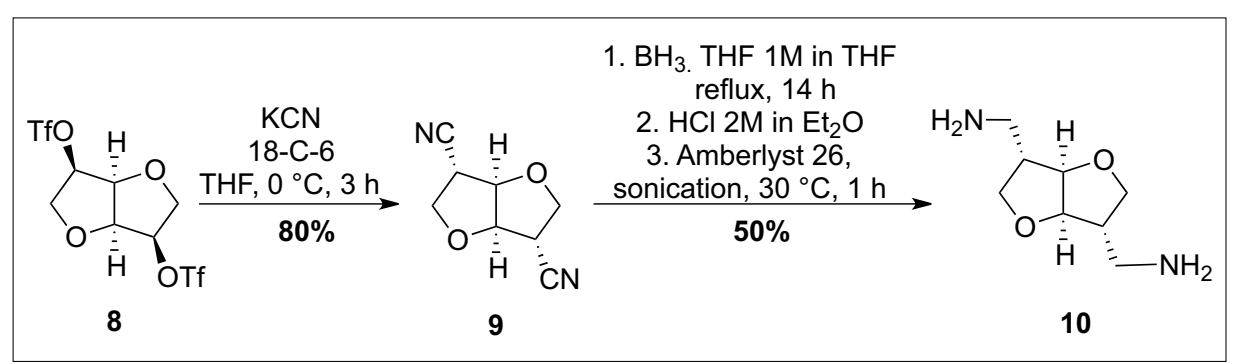

Scheme 2. Synthesis of homologated primary diamine 10.

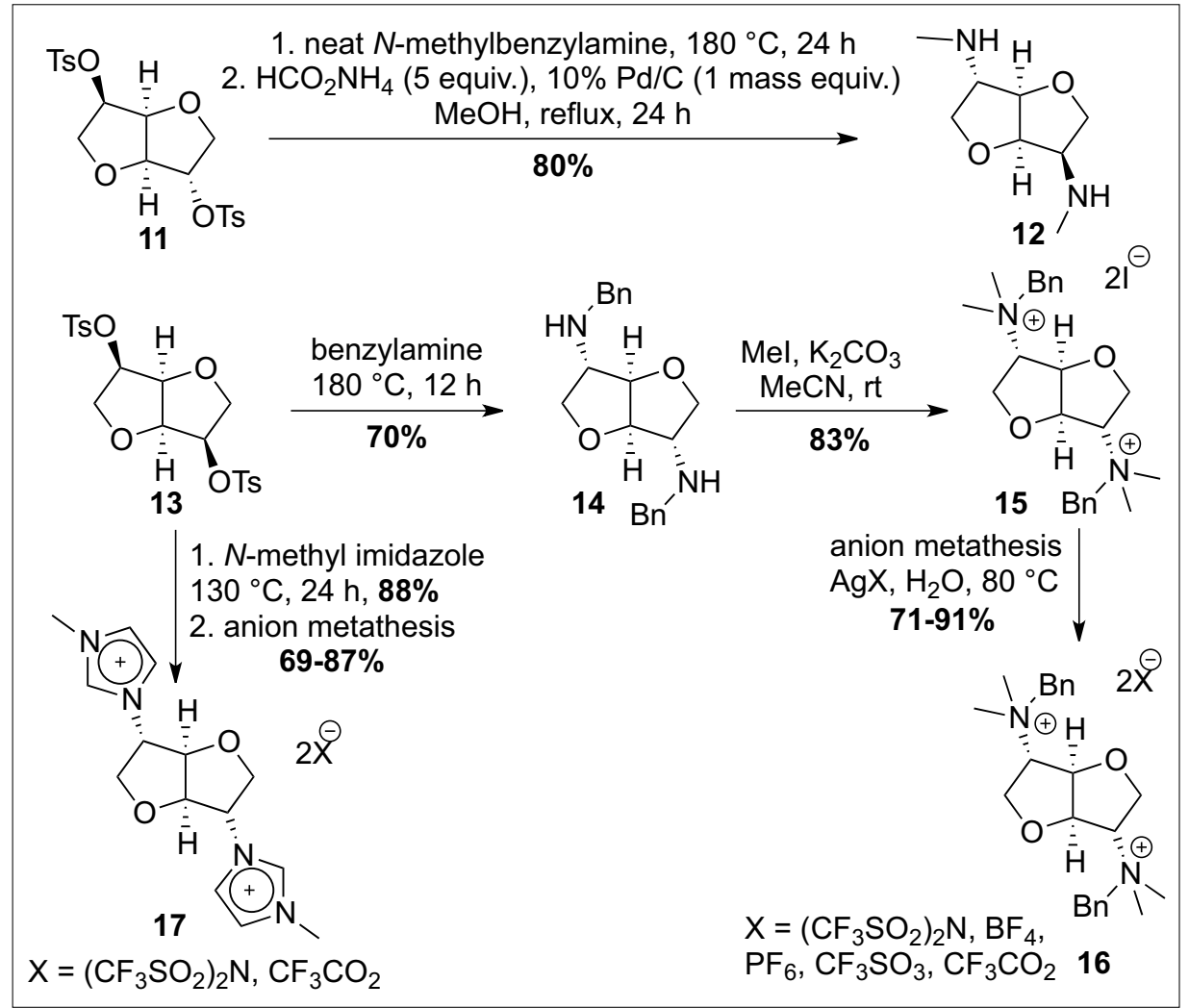

Scheme 3 . Access to secondary diamines $\mathbf{1 2}$ and $\mathbf{1 4}$ followed by quaternization to ammonium

and imidazolium salts 15-17. organic media for reactions with a high potential of recyclability as an alternative to classical solvents. Task-specific ionic liquids were also considered for their dual combination both as catalyst and solvent. As an example, chiral ionic liquids specially have shown promising applications in asymmetric synthesis, chiral chromatography or resolution. ${ }^{[32]}$ Concerns about the feedstock source, the toxicity and the poor biodegradability have also encouraged the synthesis of novel ionic liquids from biorenewable resources, ${ }^{[33]}$ like isohexides, to investigate their physico-chemical properties and applications. ${ }^{[34]}$

The synthetic sequence to provide ionic liquids $\mathbf{1 5}$ and $\mathbf{1 6}$ was generally described from isomannide ditosylate $\mathbf{1 3}$, reacting at $140-160^{\circ} \mathrm{C}$ in pure benzylamine, followed by quaternization with methyl iodide and/ or tuning the anion counterpart via metathesis. Compound 17 was prepared by direct substitution of 13 by $N$-methyl imidazole, followed by anion metathesis. 


\subsection{Preparation of Mono-amine Derivatives}

\subsubsection{Monofunctionalization of Isohexides}

The access to mono-amine derivatives is a more challenging exercise, relying on an initial single functionalization of isosorbide (or isomannide) with more or less success in the selective discrimination of hydroxyl groups. The di-functionalization is also a serious limitation to tackle.

An overview of different related substrates (18-20) available for single nucleophilic substitution is depicted in Fig. 2.

As an example, after selective monotosylation of isomannide affording 18a in $44-68 \%$ yield (side product: bis-tosylate isolated in $26 \%$ yield), the displacement of tosylate provided the amine in the exo position. If necessary, the remaining hydroxyl group could be protected as an ether $\mathbf{1 8 b}$ $(\mathrm{R}=\mathrm{Me}, \mathrm{Et} \text {, allyl, } \mathrm{Bn})^{[35]}$ or as a tert-butyl dimethylsilyl ether 18c. ${ }^{[31]}$

Given the intrinsic difference of reactivity between endo and exo positions, isosorbide was the most investigated as a starting material for monofunctionalization selectively directed on the $\mathrm{C}_{3}$ (compounds 19) or $\mathrm{C}_{6}$ position (compounds 20). Initial studies reported direct tosylation in the early sixties: a solution of isosorbide, tosyl chloride (1 equiv.) stirred in pyridine at $5{ }^{\circ} \mathrm{C}$ for $46 \mathrm{~h}$ provided endo tosylate 19a (45\% yield), its exo regioisomer 20c (12\% yield) and di-tosylate 11 (5\% yield). ${ }^{[36]}$ Direct esterification $^{[37]}$ and alkylation ${ }^{[38]}$ of isosorbide were also performed with moderate to excellent regioselectivity. In particular, the most advanced academic work concentrated on selective acetylation or benzylation of isosorbide with mechanistic propositions on the influence of the base, solvent and interactions with both hydroxyl groups determining the preferred position between $\mathrm{C}_{3}$ and $\mathrm{C}_{6}$. A large panel of experimental conditions was adjusted to turn either in favor of the exo regioisomer or the endo regioisomer (Scheme 4). Acetylation (or benzoylation) in the endo position can be carried out with $\mathrm{PbO}$ at room temperature in up to $92 \%$ yield to give 21. ${ }^{[37 b, 39]}$ The exo regioisomer 22 was obtained under relatively harsh conditions with $\mathrm{Ac}_{2} \mathrm{O}\left(\right.$ or $\left.\mathrm{Bz}_{2} \mathrm{O}\right)$ at $120^{\circ} \mathrm{C}$ in $1 \mathrm{~h}$ followed by selective hydrolysis ${ }^{[37 b]}$ or via DCC activation. ${ }^{[37 c]}$ Loupy and Quéguiner also described, in 1994, the regioselective mono-benzylation (and to a general extent mono-alkylation), tuned by the nature of the solvent and the base (Scheme 4). ${ }^{\text {38a] }}$ Thereafter, derivatives 21-25 were widely reported as valuable intermediates allowing the introduction of phenylsulfonate (20a), ${ }^{40]} p$-toluene sulfonate $(\mathbf{1 9 b}, 19 \mathrm{c}$, 20b), ${ }^{[35 a, 41]}$ or triflate $(\mathbf{2 0 d})^{[40 a]}$ as an activating group.

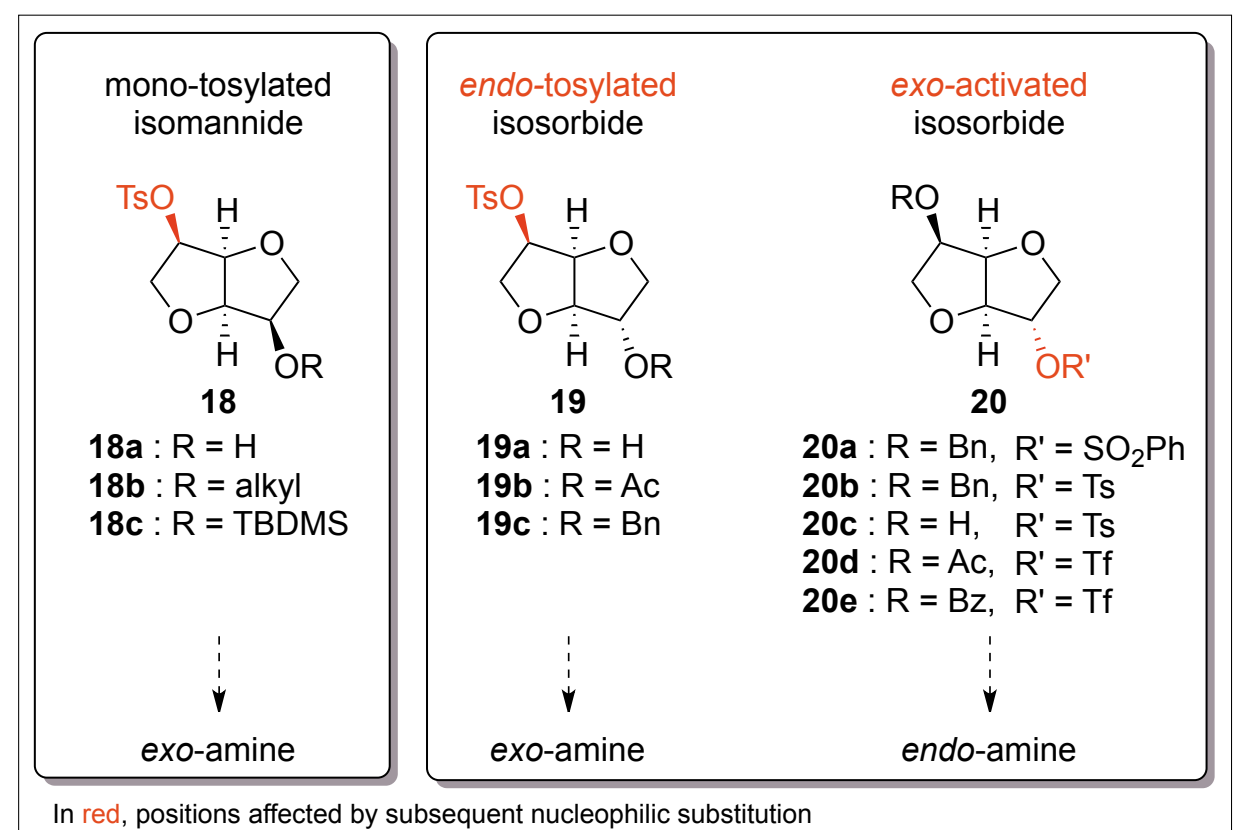

Fig. 2. Main precursors of amino isohexides arising from monofunctionalization of isomannide and isosorbide.

\subsubsection{Nucleophilic Substitution of Activated Isohexides}

Nitrogen nucleophiles used in $\mathrm{S}_{N_{2}}$ reactions on substrates shown in Fig. 2 were nearly identical to the ones used for double displacement producing diamines, with only slight changes in the reaction conditions. For the displacement of endo-tosylated molecules, compounds 18 or 19 (or their phenylsulfonate analogue [34a] were reacted with primary alkyl amines, including benzylamine. [35a,41] Sodium azide was handled in different solvents: $\mathrm{DMF},{ }^{, 42]}[\mathrm{bmim}] \mathrm{BF}_{4},{ }^{, 21,35 \mathrm{c}]}$ leading to azido derivatives with moderate to very good yields. From derivative 20a, primary alkyl amines (benzylamine, cyclohexylamine, cyclohexylmethylamine, isopropylamine, tert-butylamine) could be introduced in endo position with 56-85\% yield under classical heating or microwave irradiation. Lower yields (45 and 31\%) and epimerization were observed with aniline and $N$-ethylaniline. ${ }^{[41]} \mathrm{N}$-Methylimidazole reacted with phenylsulfonate 20a in 50\% yield after $4 \mathrm{~h}$ at $130{ }^{\circ} \mathrm{C}$. In the case of triflates $20 \mathbf{d}$ and 20e, the substitution took place at room temperature for 2 days but without any yield improvement due to significant competitive elimination (30\%) as a negative counterpart. ${ }^{[40 a]}$ The introduction of azide in endo configuration from derivatives $\mathbf{2 0}$ proved to be more difficult as an optimized $25 \%$ yield was several times reported and confirmed in our hands even using triflate as a leaving group. ${ }^{[43]}$ Free amines were obtained after hydrogenation of benzylamino derivatives or azides. ${ }^{[40 \mathrm{~b}, \mathrm{c}]}$ Methylation was performed either via an Eschweiler-Clark reaction followed by quaternization ${ }^{[34]}$ or via a phase-transfer catalyzed reaction in a biphasic medium with $\mathrm{Me}_{2} \mathrm{SO}_{4}$, to lead to mono ammonium or imidazolium derivatives. ${ }^{[35 a]}$

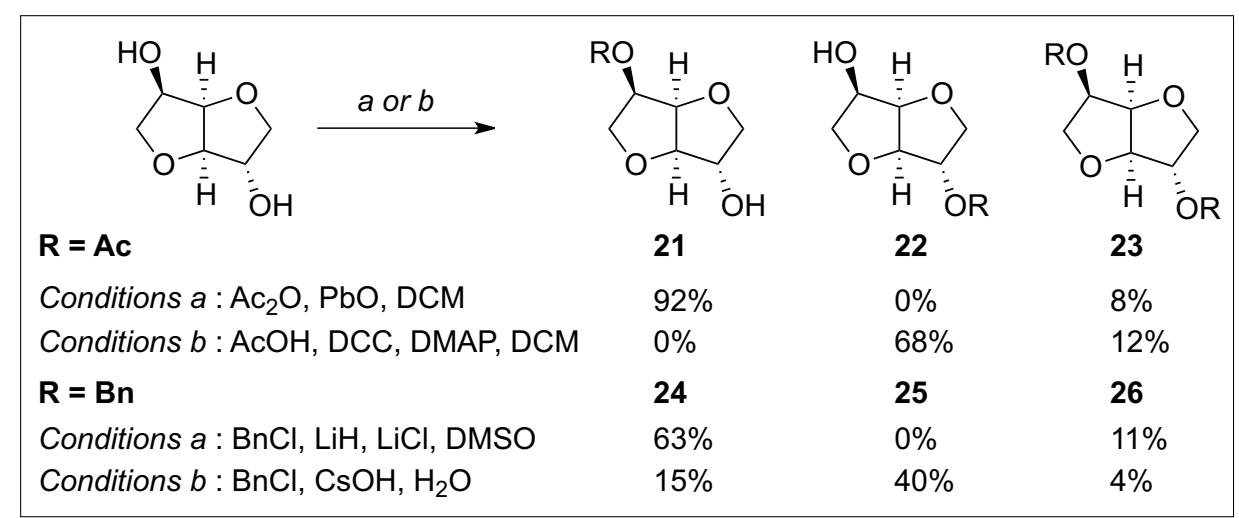

Scheme 4. Optimized conditions for regioselective acetylation/benzylation of isosorbide. 


\section{Application to Asymmetric Induction}

The potential of highly functionalized isosorbide derivatives in asymmetric catalysis as chiral auxiliaries, ${ }^{[44]}$ or ligands, ${ }^{[45]}$ has only been investigated in the last 15 years. ${ }^{[46]}$

To our knowledge, there is only one example using nitrogen-containing isohexide as a chiral auxiliary. In 1993, Quéguiner reported for the first time the synthesis of chiral aminoethers $\mathbf{2 7}^{[41]}$ and their use in the asymmetric alkylation of phenylacet amides 28 (Scheme 5). The best diastereomeric ratio was evaluated at $83 \%$ when running the reaction at $-100{ }^{\circ} \mathrm{C}$ with $\mathrm{R}_{1}=$ cyclohexyl. ${ }^{[47]}$

With the above exception, most of the disclosed reports over the last 15 years on the use of nitrogen-based isohexides for asymmetric synthesis (or chiral resolution) dealt with their role as chiral ligands or as precursors of organocatalysts.

\subsection{Organometallic Catalysis}

Enantioselective organometallic catalysis was studied with nitrogen-based ligands from isohexides especially with Diels-Alder and transfer hydrogenation reactions, which we designate model reactions.

Endolendo diamine 6, prepared in five steps (overall yield $45 \%$ ) from isomannide 2, was then converted into a set of di-imines $\mathbf{3 0}$ by reaction with substituted benzaldehydes. These di-imines were evaluated as ligands, in association with copper, zinc or magnesium in Diels-Alder reactions of cyclopentadiene and $\mathrm{N}$-crotonyl-oxazolidinone (Scheme 6). Best enantioselectivity (ee 63\%) was reached by complexation of copper (II) triflate and bidentate ligands issued from coupling with 2,6-dichlorobenzaldehyde.[25]

In contrast to the Diels-Alder reaction, asymmetric transfer hydrogenation in the presence of amino isohexides ligands, was investigated in more depth, mainly for the reduction of $\mathrm{C}=\mathrm{O}$ bonds. The $\mathrm{Ru}$ catalyzed enantioselective reduction of acetophenone was reported with different sets of ligands and then followed by other aromatic ketones (Scheme 7). The conversion of acetophenone into 1-phenylethanol proved to be efficient (ee 80\%) in the presence of $\left[\mathrm{RuCl}_{2}(p \text {-cymene })\right]_{2}(1.25 \mathrm{~mol} \%)$ with endo/endo ligand 31a (5 mol\%). ${ }^{[40 \mathrm{~b}, \mathrm{c}]}$ Diamine 31b turned out to be active but not selective $(e e<23 \%)$ while its $N$-tosylated counterpart 31c gave better conversion or selectivity depending on the Ir or Ru catalyst. In comparison, ligand 32, obtained from isosorbide after ring opening of one THF moiety, preserving the 1,2-amino alcohol sequence required for complexation with $\mathrm{Ru}^{\mathrm{II}}$ catalyst, afforded almost a quan-

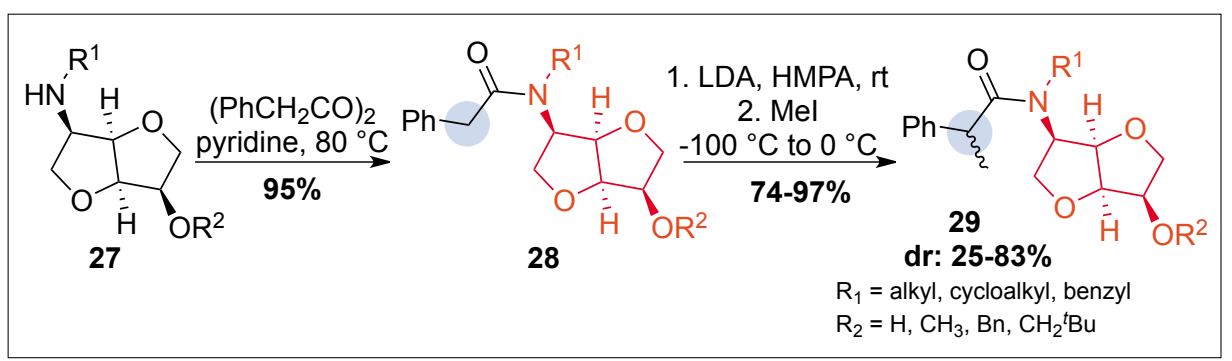

Scheme 5. Diastereoselective alkylation in $\alpha$-position of isohexide amides.

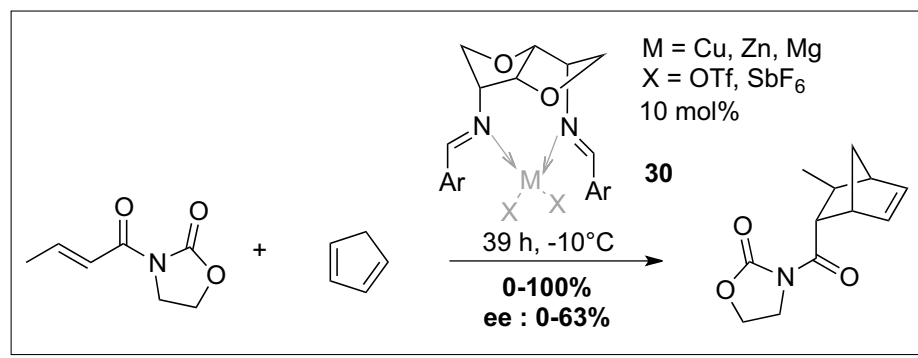

Scheme 6. Bis-imine copper-catalyzed Diels-Alder reaction.

titative conversion but a lower enantiomeric excess of $60 \%$. ${ }^{[48]}$ The presence of the chiral isosorbide part proved to be necessary, a very poor enantioselectivity (ee $<30 \%$ ) being obtained with $(S)$-2-amino2-phenylethanol or $(S)$-2-amino-3-methylbutan-1ol.[40c]

\subsection{Organocatalysis}

Organocatalysis relies on two different types of mechanism: i) covalent catalysis implying the formation of covalent intermediates between the organocatalyst and the substrate; ii) non-covalent catalysis relying on non-covalent interaction(s) such as hydrogen bonding or intermediate ionic species pairs. So far, only a few articles describe isohexide organocatalysts, the asymmetric induction being promoted either by chiral ionic liquids (or phase transfer catalysts) or thiourea derivatives, via a non-covalent mechanism.

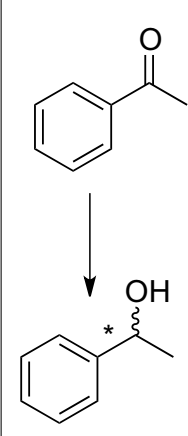

\section{Conditions A}

${ }^{t} \mathrm{BuOK},{ }^{i} \mathrm{PrOH}$

$\left[\mathrm{RuCl}_{2}(p \text {-cymene })\right]_{2} 1.25 \mathrm{~mol} \%$

ligand $5 \mathrm{~mol} \%$

$-10{ }^{\circ} \mathrm{C}, 96 \mathrm{~h}$

\section{Conditions B}

${ }^{t} \mathrm{BuOK} 1.5 \mathrm{~mol} \%$, ${ }^{i} \mathrm{PrOH}$

$\left[\mathrm{Ru} \text { (benzene) } \mathrm{Cl}_{2}\right]_{2} 1 \mathrm{~mol} \%$

ligand $1.5 \mathrm{~mol} \%$

$70{ }^{\circ} \mathrm{C}, 21 \mathrm{~h}$

\subsubsection{Chiral Ammonium or \\ Imidazolium Salts ${ }^{[34]}$}

Imidazolium derivative $\mathbf{3 3}$ and its ammonium congener 34 have been prepared and used in aza Diels-Alder reactions as chiral ionic liquids (IL). The screening of various derivatives showed that the presence of the free hydroxyl group and the non-substitution of the imidazolium nucleus were important for both reactivity and asymmetric induction (Scheme 8). Best results were obtained with IL 33 (74\% yield and $68 \%$ de). ${ }^{[34 a, 49]}$

Mono and bis-ammonium ionic liquids have also been successfully used in chiral discrimination. The diastereomeric interaction between the chiral ammonium IL and the racemic Mosher's acid silver salt was investigated (Fig. 3). ${ }^{[30,35 \mathrm{~b}]}$ A significant enhancement in the splitting of the $\mathrm{CF}_{3}$ signals could be observed with ${ }^{19} \mathrm{~F}$ NMR spectroscopy of the salt in the presence of an excess of the ionic liquid 16' or 35. The influence of the anion and of the

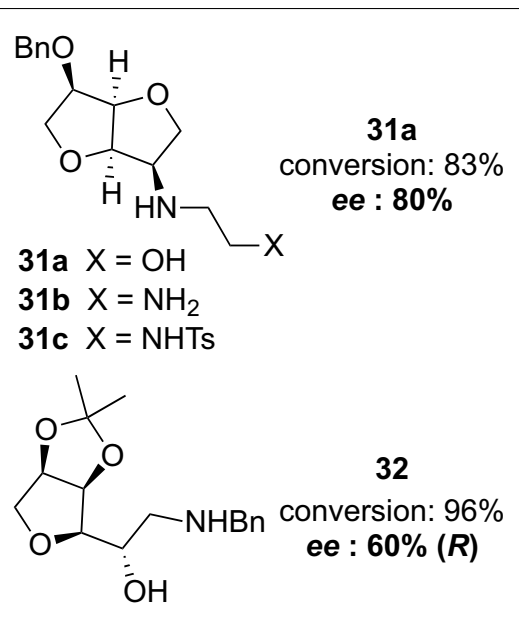

Scheme 7. Asymmetric transfer hydrogenation of acetophenone. 

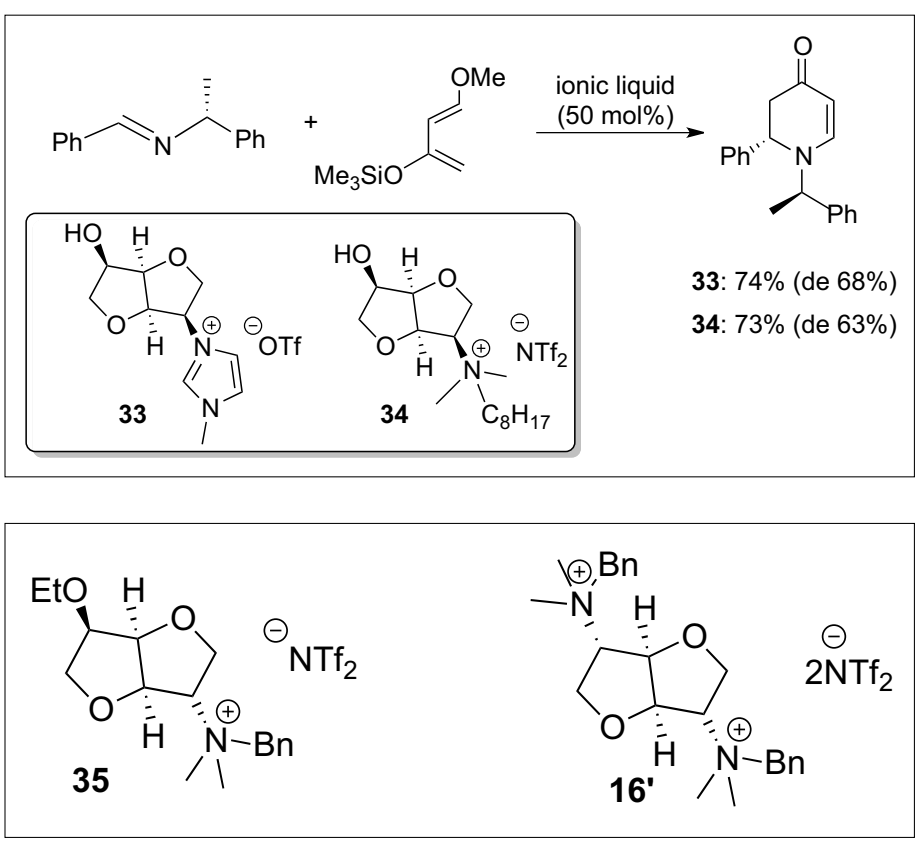

Scheme 8. Aza DielsAlder reaction in chiral isohexides IL.

Fig. 3. Mono and bisammonium ILs for chiral resolution. contributions on the 4-hydroxycoumarin nucleus, ${ }^{[54]}$ Warfarin, prepared by $\mathrm{Mi}$ chael addition of 4-hydroxycoumarin on benzalacetone, attracted logically our attention. Imidazolidine-catalyzed Michael addition was the first example reported for the asymmetric synthesis of Warfarin with an ee better than $80 \% .{ }^{[55]}$ Simple vicinal primary diamines (1,2-diaminocyclohexane, diphenyl- or dinaphthylethylenediamine $)^{[56]}$ or cinchonine derivatives (9-amino-9-deoxyepicinchona) ${ }^{[57]}$ also contributed efficiently to the formation of an iminium intermediate. Following this strategy, simple bulky aminoalcohols derived from phenylglycine represent an alternative to other chiral diamines. ${ }^{[58]}$ For a combined mechanism based on covalent/ non-covalent activation, bifunctional catalysts have been developed from previously described vicinal diamines. ${ }^{[59]}$ concentration in IL resulted in $\Delta \delta$ varying from 5 to $23 \mathrm{~Hz}$.

Some of these quaternary salts were used as phase transfer catalysts (PTC) leading to intermediate chiral ion pairs. Alkylation of $N$-(diphenylmethylene) glycine tert-butyl ester in the presence of benzyl bromide and PTC $\mathbf{3 6}$ afforded a moderate $48 \%$ ee in favor of the product with $S$-configuration (Scheme 9). [35a]

\subsubsection{Thiourea Derivatives}

Recently, Saluzzo and colleagues focused on the design of thioureas isohexidebased compounds, and their evaluation in the asymmetric Friedel-Crafts alkylation of indole with nitrostyrene. ${ }^{[50]}$ Mono and di-thioureas were prepared by tuning the stoichiometric amount of the appropriate isocyanate reacting with diamine $\mathbf{5}$ or $\mathbf{6}$. Despite a modest $44 \%$ enantiomeric excess, di-thiourea 37 was to date the first example of the potential of isohexide derivatives in asymmetric induction mediated by non-covalent interactions, and, in this case, via hydrogen bond (Scheme 10).

\subsubsection{Amines and Imines}

The same group reported the use of imines in the 1,4-addition of acetone on nitrostyrene. Organocatalyst 38 provided a low yield of $39 \%$ but a promising enantioselectivity of 59\% (Scheme 11). A mechanistic model involving 38 in equilibrium with the corresponding amines was proposed involving both covalent and non-covalent interactions. [51]

Our group is currently involved in research projects exploring synthetic applications using Michael addition, for example in the synthesis of indolizidine alkaloid $167 \mathrm{~B},{ }^{[52]}$ or for the addition of activated methylenes to non-protected nitrovinylindole in mild conditions. ${ }^{[53]}$ Due to recent

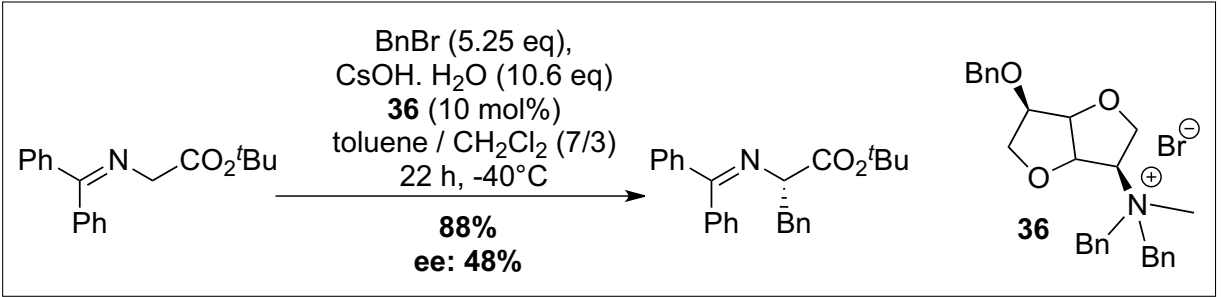

Scheme 9. Alkylation of $N$-(diphenylmethylene)glycine $t$-Bu ester.

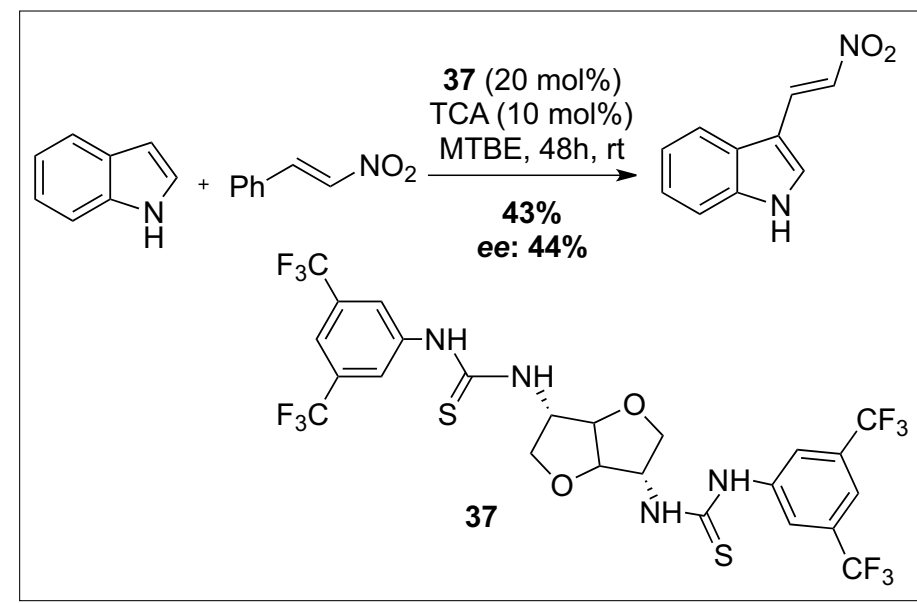

Scheme 10.

Asymmetric FriedelCrafts alkylation with thiourea 37.

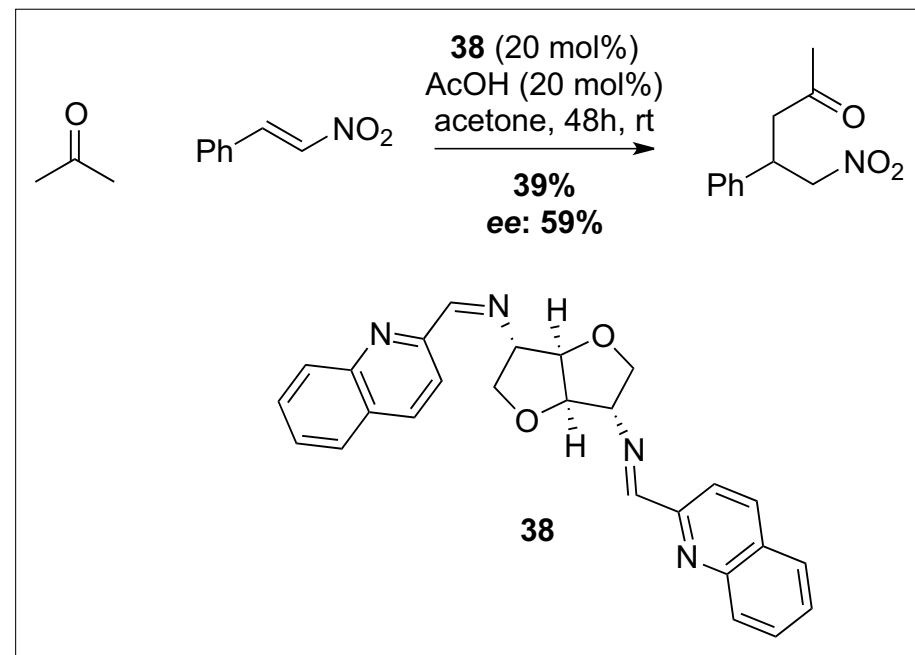

Scheme 11. Michael addition of acetone on nitrostyrene catalyzed by di-imine 38 . 
In this context, our group decided to exploit the potential of biosourced carbohydrates arising from both commercially available isosorbide and isomannide and lab-made isoidide.[25,60] Their functionalization into suitable amino alcohols, aminoethers and diamines, could provide a different option for organocatalysis. A first generation of chiral aminoalcohols, aminoethers, primary/secondary diamines were prepared following the classical synthetic pathways described in section 1 of this contribution leading to 17 potential organocatalysts (Scheme 12).

Those molecules were then screened in the asymmetric synthesis of Warfarin. Preliminary results confirmed the induction of enantioselectivity with diamine $\mathbf{5}$, but neither in a satisfying yield nor enantioselectivity (yield 20\%, ee 29\%). ${ }^{61]}$

As chiral vicinal diamines derivatives are recognized as robust organocatalysts in 1,4-addition reactions, we contemplated introducing the 1,2-diamine pattern as suggested in structure 42. A three-step sequence (peptidic coupling, reduction of amide, Boc deprotection) should provide the second generation of organocatalysts (Scheme 13).

A survey of the literature pointed out the lack of synthetic tools for the formation of amide on isohexide derivatives, only briefly reporting the use of $\beta$-aminoacids (via DCC, DMAP or EDCI, HOBt), ${ }^{[62]}$ acid chloride (with triethylamine, DMAP), [60] or oxazolone (via a ring opening by an Erlenmeyer-Plöchl reaction). ${ }^{[21,35 c]}$ Most of the well-established methods for their formation are relatively inefficient, with large quantities of potentially hazardous waste products, leading to difficult purification of the desired amides. Our laboratory recently developed a simpler method using catalytic amounts of boric acid and affording the expected amides with excellent yields. ${ }^{[63]}$ After optimization of the methodology, the coupling between amino-ether 40b and a variety of carboxylic acids was performed with good to excellent yields regardless of the nature of the carboxylic acid: benzoic acids (76-97\%), aliphatic carboxylic acids (90-96\%) and amino acids (71-85\%) (Scheme 14). A large scope of carboxylic acids and amino acids could thus be introduced leading to a diversity of new functionalized isohexide derivatives.

Perspectives of this study will specially focus on the synthetic potential of coupled derivatives with amino acids. Specifically, compound 43g and analogs will be applied in a reduction/deprotection sequence to provide corresponding vicinal diamines 42 that will be evaluated for the asymmetric synthesis of Warfarin.

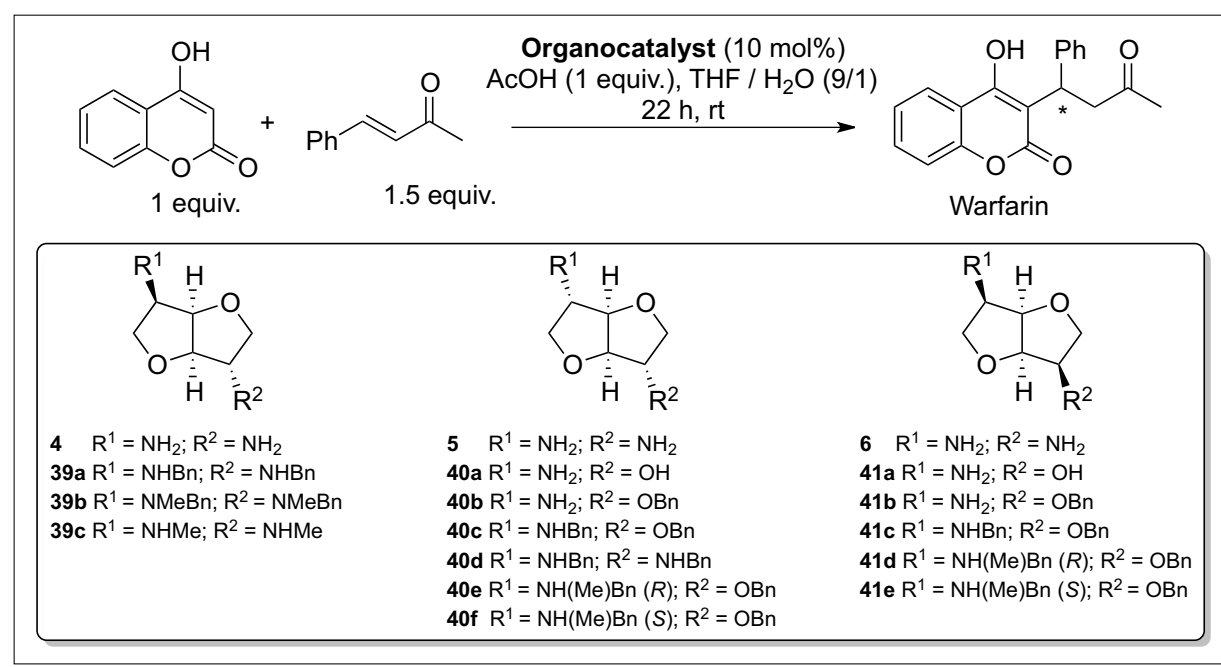

Scheme 12. Overview of the first generation of organocatalysts screened for the stereoselective synthesis of Warfarin.

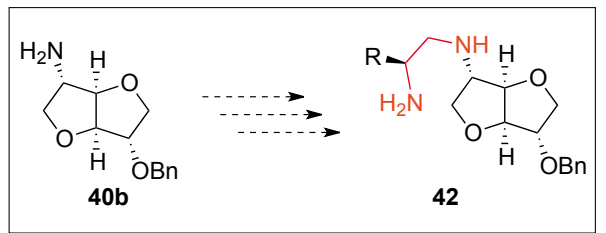

Scheme 13. Second generation organocatalysts 42.

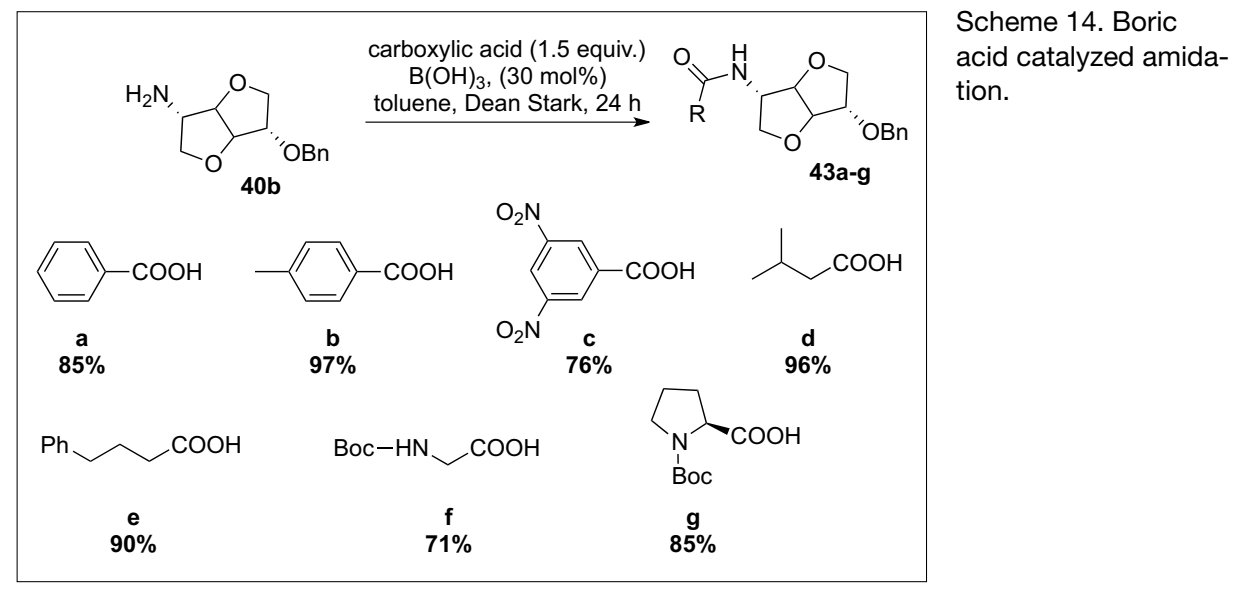

\section{Conclusion}

Isohexide derivatives have displayed their potential through different industrial applications. POLYSORB ${ }^{\circledR}$ ID37 (isosorbide diester monomer), registered in compliance with $\mathrm{REACH}$ regulations, represents an alternative to traditional plasticizers. ISORDIL ${ }^{\circledR}$ (isosorbide dinitrate) is sold as a vasodilatator, and ARLASOLVE ${ }^{\mathrm{TM}}$ DMI (dimethylisosorbide) as a new solvent. Eco-conception of molecules of high-added value is nowadays of great concern in industrial and academic laboratories. Our global strategy is to promote isohexide derivatives, that albeit known for more than 50 years, have been used only recently as a chiral platform. The attraction of isosorbide especially relies on the bio- based access to this skeleton, in accordance with the twelve fundamental principles of green chemistry. Less attention has been paid to its applications as a chiral catalyst, which probably will be developed in the next years, considering the recent publications in this field.

Received: June 5, 2015

[1] B. M. Trost, Science 1991, 254, 1471.

[2] R. A. Sheldon, Chem. Ind. 1992, 903.

[3] P. Tundo, P. Anastas, D. StC. Black, J. Breen, T. Collins, S. Memoli, J. Miyamoto, M. Polyakoff, W. Tumas, Pure Appl. Chem. 2000, 72, 1207.

[4] A. Albini, M. Fagnoni, ChemSusChem 2008, 1, 63.

[5] G. Flèche, M. Huchette, Starch 1986, 38, 26.

[6] J. Defaye, C. Pedersen, WO8900162.

[7] A. Duclos, C. Fayet, J. Gelas, Synthesis 1994, 1087. 
[8] a) W. C. Brinegar, M. Wohlers, M. A. Hubbard, E. Zey, G. Kvakovsky, T. Shockley, R. Roesky, U. Dingerdissen, W. Kind, WO0014081; b) S. J. Howards, A. J. Sanborn, WO2012015616.

[9] K. M. Moore, A. J. Sanborn, US2002/0052516.

[10] a) M. Gu, D. Yu, H. Zhang, P. Sun, H. Huang, Catal. Lett. 2009, 133, 214; b) Z.-C. Tang, D.H. Yu, P. Sun, H. Li, H. Huang, Bull. Kor. Chem. Soc. 2010, 31, 3679.

[11] M. Kurzewska, E. Skorupowa, J. Madaj, A. Konitz, W. Wojnowski, A. Wiśniewski, Carbohydr. Res. 2002, 337, 1261.

[12] J. U. Oltmanns, S. Palkovits, R. Palkovits, Appl. Catal. A: Gen. 2013, 456, 168.

[13] a) Cu-Ru: C. Montassier, J. C. Ménézo, J. Moukolo, J. Naja, L. C. Hoang, J. Barbier, J. Mol. Catal. 1991, 70, 65; b) Ni: H. Li, D. Yu, Y. Hu, P. Sun, J. Xia, H. Huang, Carbon 2010, 48, 4547; c) Pt: N. Li, G. W. Huber, J. Catal. 2010 , $270,48$.

[14] a) R. Palkovits, K. Tajvidi, J. Procelewska, R. Rinaldi, A. Ruppert, Green Chem. 2010, 12 , 972; b) G. Liang, C. Wu, L. He, J. Ming, H. Cheng, L. Zhuo, F. Zhao, Green Chem. 2011, 13, 839; c) J. Xi, Y. Zhang, D. Ding, Q. Xia, J. Wang, X. Liu, G. Lu, Y. Wang, Appl. Catal. A: Gen. 2014, 469, 108; d) P. Sun, X. Lon, H. He, C. Xia, F. Li, ChemSusChem 2013, 6, 2190.

[15] F. J. Hopton, G. H. S. Thomas, Can. J. Chem. 1969, 47, 2395.

[16] a) F. Fenouillot, A. Rousseau, G. Colomines R. Saint-Loup, J.-P. Pascault, Prog. Polym. Sci. 2010, 35, 578; b) M. Gomes, A. Gandini, A. J. D. Silvestre, B. Reis, J. Polym. Sci., Part A: Polym. Chem. 2011, 49, 3759; c) L. Jasinska, M. Villani, J. Wu, D. van Es, E. Klop, S. Rastogi, C. E. Koning, Macromolecules 2011, 44, 3458; d) R. Marín, A. Alla, A. M. de Ilarduya, S. Muñoz-Guerra, J. Appl. Polym. Sci. 2012, 123, 986; e) J. Wu, P. Eduard, L. Jasinska-Walc, A. Rozanski, B. A. J. Noordover, D. S. van Es, C. E. Koning, Macromolecules 2013, 46, 384; f) S. Thiyagarajan, J. Wu, R. J. I. Knoop, J. van Haveren, M. Lutz, D. S. van Es, RSC Adv. 2014, 4, 47937.

[17] a) S. Thiyagarajan, L. Gootjes, W. Vogelzang, J. Wu, J. van Haveren, D. S. van Es, Tetrahedron 2011, 67, 383; b) S. Thiyagarajan, L. Gootjes, W. Vogelzang, J. Wu, J. van Haveren, D. S. van Es, ChemSusChem 2011, 4, 1823.

[18] a) D.-I. Lim, H.-S. Park, J.-H. Park, J. C. Knowles, M.-S. Gong, J. Bioact. Compat. Polym. 2013, 28, 274; b) H. Kang, X. Li, J. Xue, L. Zhang, L. Liu, R. Xu, B. Guo, RSCAdv. 2014, 4, 19462.

[19] D. Lucet, T. Le Gall, C. Mioskowski, Angew. Chem. Int. Ed. 1998, 37, 2580.

[20] Chiral ligands obtained after the ring-opening of the bicyclic isohexide structure will not be discussed.

[21] T. G. Barros, S. Pinheiro, J. S. Williamson, A. Tanuri, M. Gomes Jr, H. S. Pereira, R. M. Brindeiro, J. B. A. Neto, O. A. C. Antunes, E. M. F. Muri, Amino Acids 2010, 38, 701.

[22] a) J. Kuszmann, G. Medgyes, Carbohydr. Res. 1980, 85, 259; b) J. Thiem, H. Lüders, Makromol. Chem. 1986, 187, 2775; c) J. Thiem, F. Bachmann, Makromol. Chem. 1991, 192, 2163.

[23] Diamine 5 was also obtained in quantitative yield by using the following conditions: $\mathrm{HCO}_{2} \mathrm{NH}_{4}$ (5 equiv.), $\mathrm{Pd} / \mathrm{C} 10 \%$ (1 mass equiv.), $\mathrm{MeOH}$, reflux, $24 \mathrm{~h}$.

[24] V. G. Bashford, L. F. Wiggins, J. Chem. Soc. 1950, 371 .

[25] G. De Coster, K. Vandyck, E. Van der Eycken, J. Van der Eycken, M. Elseviers, H. Röper, Tetrahedron: Asymm. 2002, 13, 1673.

[26] H. C. Kolb, M. G. Finn, K. B. Sharpless, Angew. Chem. Int. Ed. 2001, 40, 2004.

[27] a) S. Imm, S. Bähn, M. Zhang, L. Neubert, H. Neumann, F. Klasovsky, J. Pfeffer, T. Haas, M.
Beller, Angew. Chem. Int. Ed. 2011, 50, 7599; b) D. Pingen, O. Diebolt, D. Vogt, ChemCatChem 2013, 5, 2905.

[28] A. Lerchner, S. Achatz, C. Rausch, T. Haas, A. Skerra, ChemCatChem 2013, 5, 3374.

[29] a) J. Wu, P. Eduard, S. Thiyagarajan, J. van Haveren, D. S. van Es, C. E. Koning, M. Lutz, C. Fonseca Guerra, ChemSusChem 2011, 4, 599; b) J. Wu, L. Jasinska-Walc, D. Dudenko, A. Rozanski, M. R. Hansen, D. van Es, C. E. Koning, Macromolecules 2012, 45, 9333.

[30] V. Kumar, C. E. Olsen, S. J. C. Schäffer, V. S. Parmar, S. V. Malhotra, Org. Lett. 2007, 9 , 3905.

[31] M. D. R. Gomes da Silva, M. M. A. Pereira, Carbohydr. Res. 2011, 346, 197.

[32] a) L. González, B. Altava, M. Bolte, M. I. Burguete, E. García-Verdugo, S. V. Luis, Eur. J. Org. Chem. 2012, 4996; b) Y. Suzuki, J. Wakatsuki, M. Tsubaki, M. Sato, Tetrahedron 2013, 69, 9690; c) J. Li, L. Liu, Synth. Commun. 2013, 43, 476.

[33] a) S. Hu, T. Jiang, Z. Zhang, A. Zhu, B. Han, J. Song, Y. Xie, W. Li, Tetrahedron Lett. 2007, 48, 5613; b) C. Chiappe, A. Marra, A. Mele, Top. Curr. Chem. 2010, 295, 177.

[34] a) O. N. Van Buu, A. Aupoix, N. D. T. Hong, G. Vo-Thanh, New J. Chem. 2009, 33, 2060; b) T. K. T. Truong, N. V. B. Olivier, A. Aupoix, B. Pegot, G. Vo-Thanh, Curr. Org. Synth. 2012, 9 , 53.

[35] a) S. Kumar, U. Ramachandran, Tetrahedron 2005, 61, 4141; b) V. Kumar, C. Pei, C. E. Olsen, S. J. C. Schäffer, V. S. Parmar, S. V. Malhotra, Tetrahedron: Asymmetry 2008, 19, 664; c) T. G. Barros, S. Pinheiro, J. S. Williamson, A. Tanuri, H. S. Pereira, R. M. Brindeiro, J. B. A. Neto, O A. C. Antunes, E. M. F. Muri, Synthesis 2009, 620 .

[36] a) R. U. Lemieux, A. G. McInnes, Can. J. Chem. 1960, 136; b) G. I. Kurochkina, G. S. Bratash, N. O. Soboleva, L. K. Vasyanina, M. K. Grachev, E. E. Nifant'ev, Russ. J. Gen. Chem. 2004, 74, 1616.

[37] a) K. W. Buck, J. M. Duxbury, A. B. Foster, A. R. Perry, J. M. Webber, Carbohydr. Res. 1966, 2, 122; b) P. Stoss, P. Merrath, G. Schlüter, Synthesis 1987, 174; c) Z. Čeković, Z. Tokić, Synthesis 1989, 610.

[38] a) D. Abenhaïm, A. Loupy, L. Munnier, R. Tamion, F. Marsais, G. Quéguiner, Carbohydr. Res. 1994, 261, 255; b) F. Liu, K. De Oliveira Vigier, M. Pera-Titus, Y. Pouilloux, J.-M. Clacens, F. Decampo, F. Jérôme, Green Chem. 2013, 15, 901.

[39] a) C. Berini, A. Lavergne, V. Molinier, F. Capet, E. Deniau, J.-M. Aubry, Eur. J. Org. Chem. 2013, 1937; b) L. Pickering, V. Nair, Nucleos. Nucleot. Nucl. 1996, 15, 1751.

[40] a) O. N. Van Buu, A. Aupoix, G. Vo-Thanh, Tetrahedron 2009, 65, 2260; b) K. D. Huynh, H. Ibrahim, M. Toffano, G. Vo-Thanh, Tetrahedron: Asymmetry 2010, 21, 1542; c) K. D. Huynh, H. Ibrahim, E. Kolodziej, M. Toffano, G. Vo-Thanh, New J. Chem. 2011, 35, 2622.

[41] R. Tamion, F. Marsais, P. Ribereau, G. Quéguiner, Tetrahedron: Asymmetry 1993, 4, 1879.

[42] F. Bachmann, J. Reimer, M. Ruppenstein, J. Thiem, Macromol. Rapid Commun. 1998, 19, 21

[43] a) C. Besset, S. Binauld, M. Ibert, P. Fuertes, J.-P. Pascault, E. Fleury, J. Bernard, E Drockenmuller, Macromolecules 2010, 43, 17; b) According to ref. [41], $60 \%$ yield in azide could be obtained from 20a with $\mathrm{NaN}_{3}$ in DMSO at $120^{\circ} \mathrm{C}$.

[44] a) A. Loupy, D. Monteux, Tetrahedron Lett. 1996, 37, 7023; b) M.-H. Xu, W. Wang, L.-J. Xia, G.-Q. Lin, J. Org. Chem. 2001, 66, 3953; c) M.-H. Xu, W. Wang, G.-Q. Lin, Org. Lett. 2000, 2, 2229; d) D. Riber, T. Skrydstrup, $\mathrm{Org}$ Lett. 2003, 5, 229; e) A. Loupy, D. A. Monteux,
Tetrahedron 2002, 58, 1541; f) E. J. Enholm, J. S. Cottone, F. Allais, Org. Lett. 2001, 3, 145; g) E. J. Enholm, J. S. Cottone, Org. Lett. 2001, 3, 3959.

[45] a) A. Dervisi, C. Carcedo, L.-L. Ooi, $A d v$. Synth. Catal. 2006, 348, 175; b) H. Ibrahim, C. Bournaud, R. Guillot, M. Toffano, G. VoThanh, Tetrahedron Lett. 2012, 53, 4900.

[46] M. Kadraoui, T. Maunoury, Z. Derriche, S. Guillarme, C. Saluzzo, Eur. J. Org. Chem. 2015 , 3,441 .

[47] R. Tamion, F. Marsais, P. Ribereau, G. Quéguiner, Tetrahedron:Asymmetry 1993, 4, 2415.

[48] a) S. Guillarme, T. X. M. Nguyen, C. Saluzzo, Tetrahedron: Asymmetry 2008, 19, 1450; b) T. T. Le, S. Guillarme, C. Saluzzo, Tetrahedron 2010, 66, 8893.

[49] O. N. Van Buu, G. Vo-Thanh, Lett. Org. Chem. 2007, 4, 158

[50] L. Y. Chen, S. Guillarme, C. Saluzzo, Arkivoc 2013, 227.

[51] L.-Y. Chen, S. Guillarme, A. Whiting, C. Saluzzo, Arkivoc 2014, 215.

[52] S. Gracia, R. Jerpan, S. Pellet-Rostaing, F Popowycz, M. Lemaire, Tetrahedron Lett. 2010, 51, 6290.

[53] M. Baron, E. Métay, M. Lemaire, F. Popowycz, J. Org. Chem. 2012, 77, 3598.

[54] a) A. Montagut-Romans, M. Boulven, M. Lemaire, F. Popowycz, New J. Chem. 2014, 38, 1794; b) B. Matagrin, A. Montagut-Romans, M. Damin, M. Lemaire, F. Popowycz, E. Benoit, V. Lattard, J. Clin. Pharm. 2014, 54, 896.

[55] N. Halland, T. Hansen, K. A. Jørgensen, Angew. Chem. Int. Ed. 2003, 42, 4955.

[56] a) H. Kim, C. Yen, P. Preston, J. Chin. Org. Lett. 2006, 8, 5239; b) M. Rogozińska, A. Adamkiewicz, J. Mlynarski, Green Chem. 2011, 13, 1155; c) Y. Liu, X. Liu, M. Wang, P. He, L. Lin, X. Feng, J. Org. Chem. 2012, 77, 4136; d) M. Rogozińska, J. Mlynarski, Tetrahedron: Asymmetry 2014, 25, 813.

[57] J.-W. Xie, L. Yue, W. Chen, W. Du, J. Zhu, J.-G. Deng, Y.-C. Chen, Org. Lett. 2007, 9, 413.

[58] T. E. Kristensen, K. Vestli, F. K. Hansen, T. Hansen, Eur. J .Org. Chem. 2009, 5185.

[59] a) Linked to amino acids: S. Ma, L. Wu, M. Liu, Y. Wang, Org. Biomol. Chem. 2012, 10, 3721 b) Ts-DPEN: H.-M. Yang, L. Li, K.-Z. Jiang, J.-X. Jiang, G.-Q. Lai, L.-W. Xu, Tetrahedron 2010, 66, 9708; c) Imines: X. Zhu, A. Lin, Y. Shi, J. Guo, C. Zhu, Y. Cheng, Org. Lett. 2011, 13, 4382; d) Primary amine thiourea bifunctional catalyst: R.-Q. Mei, X.-Y. Xu, Y.-C. Li, J.-Y. Fu, Q.-C. Huang, L.-X. Wang, Tetrahedron Lett. 2011, 52, 1566; e) Tagged to an ionic group: A. S. Kucherenko, V. G. Lisnyak, A. O. Chizhov, S. G. Zlotin, Eur. J. Org. Chem. 2014, 3808; f) Primary amine-phosphinamide bifunctional catalyst: J. Dong, D.-M. Du, Org. Biomol. Chem. 2012, 10, 8125; g) Zwitterionic ammonium sulfonate: M. Leven, J. M. Neudörfl, B. Goldfuss, Beilstein J. Org. Chem. 2013, 9, 155.

[60] G. P. Dillon, J. M. Gaynor, D. Khan, C. G. Carolan, S. A. Ryder, J. F. Marquez, S. Reidy, J. F. Gilmer, Bioorg. Med. Chem. 2010, 18, 1045.

[61] Chiral HPLC method: Column: Lux Cellulose 1; Eluent: hexane-isopropanol-formic acid (60 / 40 / 0.1); $40{ }^{\circ} \mathrm{C}, 1 \mathrm{~mL} / \mathrm{min}$, MWL detection at $210,230,280 \mathrm{~nm}$.

[62] a) T. G. Barros, B. C. Zorzanelli, S. Pinheiro, M. A. de Brito, A. Tanuri, E. C. B. da Costa, R. S. Mohana-Borges, C. R. Rodrigues, A. T. M. Souza, V. F. Ferreira, E. M. F. Muri, Lett. Org. Chem. 2012, 9, 239; b) E. M. F. Muri, M. Gomes, M. G. Albuquerque, E. F. F. da Cunha, R. B. de Alencastro, J. S. Williamson, O. A. C. Antunes, Amino Acids 2005, 28, 413.

[63] M. Janvier, S. Moebs-Sanchez, F. Popowycz, submitted for publication. 